\title{
Descriptive Study of Septicemia among Children Under Five Years in Wasit Province, Iraq in 2019
}

\author{
Rana H. Raheema ${ }^{1}$, Ban H. Qaddoori ${ }^{1}$

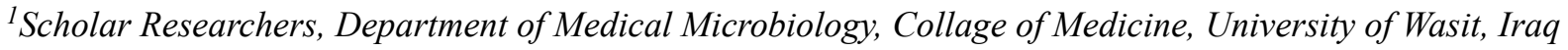

\begin{abstract}
Sepsis is a common illness; however, it strikes aged people and very young people in more tendency. The most susceptible age group of sepsis is children, and more specifically newborns and young infants. In addition, underlying health problems increase the risk of illness. The aim of this study is to determine prevalence of septicemia in children under five years in Al-Kut hospital for Gynecology obstetrics and pediatrics, numbers of cases are 135 patients. A descriptive analysis study design was used for the purpose is conducted at Al-Kut hospital for Gynecology obstetrics and pediatrics. There was significant differences in the prevalence of septicemia among children with different ages. The prevalence of septicemia was higher in the $1^{\text {st }}$ month of age .Generally, prevalence of septicemia did not significantly affected by gender, however age is the most influencer since the infection was higher in children samples which were collected from stool isolates. At end, to reduce the complication and mortality of septicemia and to prevent sepsis formation infection including antibiotic-resistant pathogens related infection, research recommend a rapid diagnosis and effective treatment.
\end{abstract}

Keywords: Descriptive epidemiology, Septicemia, Children.

\section{Introduction}

Infected of blood with bacteria is named as septicemia and causing a sepsis. It is also called "blood poisoning", and this term come from the idea that the infectious bacteria poison the blood by itself or their toxins. ${ }^{(1)}$. Generally, any positive blood culture with systemic bacterial infection consider as septicemia ${ }^{(2)}$. It is a common cause of morbidity and mortality in children (3). According to $\mathrm{WHO}$, about $85 \%$ of deaths in newborn resulting from infections, including tetanus, pneumonia, and sepsis. The later cause lead to death in about $40 \%$ of affected infants most of them in developing countries (4). In addition, mortality and hospitalization is common in children affected by septic shock around the world ${ }^{(6)}$.

Globally, every year about 3 million newborns and 1.2 million children had an infection lead to sepsis ${ }^{(8)}$. The resistant pathogens count to be a cause of sepsis leading death in 3 out of 10 in neonatal ${ }^{(9)}$. Although it a major cause of global morbidity and mortality, sepsis still lacking of targeted therapy ${ }^{(5,6)}$.

Every year more than 75,000 infant and children in the U.S. develop severe sepsis. Almost 7,000 of them die, and this number is more than deaths from cancer in children (American Academy of Pediatrics, 2017). The aim of this study to identify prevalence of septicemia in children under five years.

\section{Materials and Method}

A descriptive analysis study design was used in collect data,after taking permission from the Laboratory Unit Officer at al-kut hospital for maternity and pediatric, the data was taken from bacteriology unit that affiliate to microbiology Laboratory on ( $5^{\text {th }}$ August, 2019). A total of 135 number of cases were collected from children suffering with septicemia under five years and for both sex (70 male and 65 female) during a period from $1^{\text {st }}$ January 2019 to $30^{\text {th }}$ June 2019 (it is mean the first 6 month of 2019), the data recorded the type of samples that were used to diagnose septicemia among the children such as urine, stool, blood, and throat swab.

Data Analysis: In order to determine whether the objectives of the study have met or not, that data of the present study has been analyzed through application of the descriptive statistical (Microsoft Excel2010) analysis approach. The researcher divided children ages to five 
age groups which include Group one from 1 month to 12 months, Group two from 13 months to 24 months, Group three from 25 months to 36 months, Group four from 37 months to 48 months and Group five from 49 months to 60 months.

\section{Results}

Septicemia is a major cause of death in neonates and children. A total of 135 children with septicemia under five years in Al-Kut hospital for Gynecology obstetrics and pediatrics, table (1). There was significant differences in the prevalence of septicemia among children with different ages, the prevalence of septicemia was higher in the $1^{\text {st }}$ month of age $\mathrm{P}<0.001$, as shown in table (2). Newborns, and young children with age less than 1 year are more susceptible for sepsis than older children and adults because of under development of their immune systems.

Table (1): The characteristic of cases

\begin{tabular}{|l|c|}
\hline No. of cases & 135 \\
\hline Ages & $1-60$ \\
\hline Mean \pm SD & $11.488 \pm 13.724$ \\
\hline Minimum & 1 \\
\hline Maximum & 60 \\
\hline
\end{tabular}

Table (2): The correlation between cases ages

\begin{tabular}{|c|c|c|c|c|c|}
\hline \multirow{2}{*}{ Age/Months } & \multirow{2}{*}{ Frequency } & \multirow{2}{*}{ Valid \% } & \multicolumn{2}{|c|}{ 95\% Confidence Interval } & \multirow{2}{*}{$\begin{array}{c}\text { Significance } \\
\text { (t-test) }\end{array}$} \\
\hline & & & Lower & Upper & \\
\hline 1 & 27 & $20.0 \%$ & \multirow{21}{*}{\multicolumn{2}{|c|}{$(9.152683-13.825095)$}} & \multirow{21}{*}{$\begin{array}{l}\mathrm{t}=9.726 \\
P<0.001\end{array}$} \\
\hline 2 & 17 & $12.6 \%$ & & & \\
\hline 3 & 6 & $4.4 \%$ & & & \\
\hline 4 & 2 & $1.5 \%$ & & & \\
\hline 5 & 9 & $6.7 \%$ & & & \\
\hline 6 & 12 & $8.9 \%$ & & & \\
\hline 7 & 5 & $3.7 \%$ & & & \\
\hline 8 & 5 & $3.7 \%$ & & & \\
\hline 9 & 3 & $2.2 \%$ & & & \\
\hline 11 & 3 & $2.2 \%$ & & & \\
\hline 12 & 10 & $7.4 \%$ & & & \\
\hline 13 & 1 & $0.7 \%$ & & & \\
\hline 15 & 1 & $0.7 \%$ & & & \\
\hline 16 & 1 & $0.7 \%$ & & & \\
\hline 18 & 4 & $3.0 \%$ & & & \\
\hline 20 & 2 & $1.5 \%$ & & & \\
\hline 24 & 14 & $10.4 \%$ & & & \\
\hline 36 & 5 & $3.7 \%$ & & & \\
\hline 48 & 5 & $3.7 \%$ & & & \\
\hline 60 & 3 & $2.2 \%$ & & & \\
\hline Total & 135 & $100.0 \%$ & & & \\
\hline
\end{tabular}

Male and female have no significant difference in the prevalence of septicemia with percentage of $51.9 \%$ and $48.1 \%, P=0.666$, for male and female respectively as shown in table (3). Mugalu et al., ${ }^{(10)}$ finding does not agree with this data since he reported significant difference with higher prevalence in the females. This difference has no apparent reason, however it may due to geographical origin. 
Table (3): Effect of gender on the prevalence of septicemia

\begin{tabular}{|l|c|c|c|}
\hline Gender & Frequency & Valid \% & Significance (Pearson's chi-square test) \\
\hline Male & 70 & $51.9 \%$ & $X^{2}=0.185$ \\
\cline { 1 - 3 } Female & 65 & $48.1 \%$ & $P=0.666$ \\
\hline Total & $\mathbf{1 3 5}$ & $\mathbf{1 0 0 . 0} \%$ & \\
\hline
\end{tabular}

In our study, septicemia prevalence were detected in all age groups, result showed that the most cases were occurred among children in first age groups (1-12) moths. Table (4).

Table (4): The distribution of ages group

\begin{tabular}{|l|c|c|c|}
\hline Age/Months & Frequency & Valid \% & Significance (Pearson's chi-square test) \\
\hline $1-12$ & 99 & $73.3 \%$ & \\
\hline $13-24$ & 23 & $17.0 \%$ & \multirow{2}{*}{$\mathrm{X}^{2}=249.777$} \\
\hline $25-36$ & 5 & $3.7 \%$ & \\
\hline $37-48$ & 5 & $3.7 \%$ & \\
\hline $49-60$ & 3 & $2.2 \%$ & \\
\hline Total & $\mathbf{1 3 5}$ & $\mathbf{1 0 0 . 0} \%$ & \\
\hline
\end{tabular}

The prevalence of septicemia from different samples in children was significantly differences $P<0.001$. Results in this study showed high septicemia among children which were collected from stool isolates than isolates collected from blood, urine and throat as shown in table (5).
Isolation of offending pathogen by bacteriological culture still the mainstay of definitive diagnosis of septicemia (3). Organisms isolated from the stool of children with sepsis vary from area to area.

Table (5): The collected samples frequencies

\begin{tabular}{|l|c|c|c|}
\hline Samples & Frequency & Valid \% & Significance (Pearson's chi-square test) \\
\hline Urine & 60 & $44.4 \%$ & $X^{2}=105.859$ \\
Stool & 67 & $49.6 \%$ & $P 001$ \\
Blood & 6 & $4.4 \%$ & \\
\hline Throat & 2 & $1.5 \%$ & $\mathbf{1 0 0 . 0} \%$ \\
\hline Total & $\mathbf{1 3 5}$ & & \\
\hline
\end{tabular}

\section{Conclusion}

From the analysis we found that increased frequency of septicemia in the children whose age group is 1 month to 12 months, and Particularly in age of 1 month and below. The present decreases to the low value with increase of age .There is Simple difference between male and female (little increase in male). Stool sample is the more one that used in diagnosis of septicemia, depend on the come cause of this disease, followed by urine sample, Rapid diagnosis and effective treatment to reduce mortality and complications of septicemia, and preventing sepsis from infections including antibioticresistant pathogens infection.

\section{Conflict of Interest: None}

Funding: Self

Ethical Clearance: Not required

\section{References}

1. Pellectier Jr, L.L. Microbiology of the circulatory system. Baron, S, editor. Medical Microbiology. 
(4th Edn) Gaveston, Texas: The University of Texas Medical Branch. 1991. 1117-23.

2. Misallati A., El-Bargathy, S. Shembesh, N. Blood culture proven neonatal septicaemia: a review of 36 cases. Eastern Mediterr Health. J. 2000. 6:483-86.

3. Meremikwu, M.M., Nwachukwu, C.E., Asuquo, A.E., Okebe, J.U. Utsalo, S.J. Bacterial isolates from blood culture of children with suspected septicaemia in Calabar, Nigeria. BMC Infect. Dis. 2005. 5:110. doi:10.1186/1471 - 2334 - 5 - 110 .

4. World Health Organization. Essential newborn care. A report of a Technical Working Group 2005. pg 16.

5. Weiss SL, Fitzgerald JC, Pappachan J, Wheeler D, Jaramillo-Bustamante JC, Salloo A, Singhi SC, Erickson S, Roy JA, Bush JL, Nadkarni VM, Thomas NJ. Sepsis Prevalence, Outcomes, and Therapies (SPROUT) Study Investigators and Pediatric Acute Lung Injury and Sepsis Investigators (PALISI) Network Global epidemiology of pediatric severe sepsis: the sepsis prevalence, outcomes, and therapies study. Am J Respir Crit Care Med 2015.191: 1147-1157.
6. Opal SM The current understanding of sepsis and research priorities for the future. Virulence 2014. 5: $1-3$

7. Watson RS, Carcillo JA, Linde-Zwirble WT. The epidemiology of severe sepsis in children in the United States. Am J Respir Crit Care Med. 2003;167(5):695-701

8. Fleischmann-Struzek C, Goldfarb DM, Schlattmann P, Schlapbach LJ, Reinhart K, Kissoon N. The global burden of paediatric and neonatal sepsis: a systematic review. The Lancet Respiratory medicine 2018; 6(3): 223-30.

9. Laxminarayan R, Matsoso P, Pant S. Access to effective antimicrobials: a worldwide challenge. Lancet 2016. 387(10014): 168-75.

10. Mugalu, J., Nakakeeto, M.K., Kiguli, S., Kaddu, D.H., Mulindwa. Aetiology, risk factors and immediate outcome of bacteriological confirmed neonatal septicaemia in Mulago Hospital, Uganda. Afr. Health. Sci. 2006. 6(2):120-26. 